\begin{tabular}{l} 
Processed cheeses belong to food products of high nutri- \\
tional and biological value. Bioflavonoids, which are wide- \\
spread in higher plants and have a number of unique prop- \\
erties, are practically not found in traditional processed \\
cheese chunks. Quercetin is most commonly found in plant \\
flavonoids. Most studies have confirmed the following basic \\
biological properties of quercetin: immunostimulating effect \\
(increases the activity of phagocytes, T-and B-lymphocytes; \\
increases the production of antibodies, reduces the manifes- \\
tations of secondary immunodeficiency, the incidence of \\
viral infections); oncoprotective effect due to a decrease in \\
the damaging effect of oxygen radicals on the genetic appa- \\
ratus; antioxidant protection; positive effect in cardiovas- \\
cular diseases, etc. The cheapest, most bioavailable and \\
frequently used plant raz materials are onions, which also \\
contain bioflavonoids. The article explores the use of wild \\
onions in the creation of functional processed cheese. In con- \\
nection with the spread of coronavirus infection, it is nec- \\
essary to strengthen the body's immunity with the help of \\
nutrition. The experiments carried out have established the \\
quantitative presence of flavonoids, vitamin K in processed \\
cheese with wild onions. Inulin and saponins were found in \\
the composition of wild onions, which also proves the advis- \\
ability of using wild onions in food. The research results on \\
the development of a technology for a new processed cheese \\
and a method of adding wild onion filler in different varia- \\
tions: fresh and in the form of a powder are presented. It was \\
found that fresh addition of Allium odorum imparts a sharp \\
onion aroma, and when dried it imparts a slightly chalky \\
aroma to the final product. The positive effect of the vegeta- \\
ble filler on the shelflife of processed cheese has been proven \\
Keywords: food, wild onions, coronovirus, processed \\
cheeses, vegetable fillers, Allium odorum, flavonoids \\
\hline
\end{tabular}

UDC 664

DOI 10.15587/1729-4061.2021.239120

\section{REVEALING THE FEATURES OF THE FORMATION OF THE PROPERTIES OF PROCESSED CHEESE WITH WILD ONIONS}

\author{
Mariam Alimardanova \\ Doctor of Technical Sciences, Professor, \\ Academician of Academy of Agricultural Sciences \\ of Republic of Kazakhstan* \\ Dinara Tlevlessova \\ Corresponding author \\ $\mathrm{PhD}$, Associate Professor* \\ E-mail: tlevlessova@gmail.com \\ Venera Bakiyeva \\ Master of Technical Sciences* \\ Zhandos Akpanov \\ Master of Economical Sciences \\ Department of Quality and \\ Safety of Food Products** \\ *Department of Food Technology** \\ **Almaty Technological University \\ Tole bi str., 100, Almaty, \\ Republic of Kazakhstan, 050012
}

How to Cite: Alimardanova, M., Tlevlessova, D., Bakieva, V., Akpanov, Z. (2021). Revealing the features of the formation of

\section{Introduction}

Recently, the processed cheese market has been gaining a stable leading position in the Kazakhstan market in comparison with other types of cheese. A relatively simple technology for the production of processed cheeses makes it possible to obtain products with a wide range of organoleptic parameters that can satisfy a variety of consumer tastes. In addition, the long shelf life, affordable prices, convenient packaging and attractive packaging contribute to the large popularity of processed cheeses among the population, which stimulates an increase in their production volumes and an expansion of the range.

The data accumulated in the field of nutritiology indicate that in the living conditions of a modern person it is impossible to adequately meet the body's needs with all food and minor biologically active components necessary to maintain its vital activity, due to traditional nutrition [2]. The main requirements for functional products is their harmlessness, i.e. the absence of harmful synthetic additives in their composition and a high content of natural biologically active substances (BAA) in plant raw materials, such as aromatic substances, L-ascorbic acid, phenolic compounds, vitamins, minerals, kapotinoids, etc.
The scientific basis of modern food production is the search for new resources of irreplaceable food components, the use of non-traditional types of raw materials, the creation of new progressive technologies that make it possible to increase the nutritional and biological value of the product, give it the desired properties, and increase the shelf life. In world practice, one of the most common ways to adjust the composition of products is the combination of raw materials with components of plant and animal origin [3].

Garlic (Allium satioum L.) is considered one of the twenty essential vegetables used either as a raw vegetable in cooking or as an ingredient in traditional and modern medicine. It is one of the richest sources of total phenolic compounds among commonly consumed vegetables, and has been praised for the contribution of phenolic compounds to the human diet [4].

Onions (Allium cepa L.) and garlic (Allium sativum L.), one of the oldest cultivated plants, which are used for food and medicinal purposes. Plants are a rich source of several phytonutrients recognized as essential elements of the diet. They are used to treat and prevent a number of diseases, including cancer, coronary heart disease, hypercholesterolemia, type 2 diabetes, hypertension, cataracts, obesity, and gastrointestinal disorders. These actions are due to thiosulfinates, volatile sulfur compounds that are also responsible 
for the pungent taste of these vegetables. In addition to these low molecular weight compounds, onions and garlic are characterized by more polar compounds of phenolic and steroid origin, often glycosylated. These latter compounds, in comparison with the more studied thiosulfinates, have the advantage that they are not caustic and are more stable during cooking [5].

Onions and their by-products are high in antioxidants, which means they can scavenge free radicals. It has good anti-inflammatory and anti-mutagenic properties. It was found that lipid peroxidation is inhibited in rat liver microcosms, and also efficiently absorbs superoxide anions [6].

The data presented allows to assert the need for research on onions and the functional properties of food products with them.

\section{Literature review and problem statement}

Analysis of scientific and technical information has shown that all types of onions contain powerful antioxidants, sulfur and numerous phenolic compounds, have antioxidant, antibacterial and antifungal effects [7].

The antioxidant properties of onions as a by-product have also been confirmed when onion extracts are added to meat products. Fresh, frozen and pre-cooked pork chops were further tested to verify the antioxidant efficacy of the onion extract. Due to the inclusion of onion extract in the product, the shelf life of all products was increased, which was determined by the value of TBA (thiobarbituric acid) [8].

Previous studies have shown an increase in the shelf life of processed cheese, in the production of which fresh Allium odorum onions were used, in the form of an extract from the dried ground part of the plant [9].

The onion in the product has strong antibacterial properties. In vitro studies have shown that the active components of onion in the composition of the product limit the growth of Streptocossi, Staphylocossi, Proteus sp., Escherichia coli and Salmonella [10]. Meena [11, 12] reported that at ambient temperature fresh onion juice exhibits an inhibitory effect against $S$. cerevisiae, A. niger, Musoderma spp. and L. acidophilus by $4,10,12$, and $14 \%$, respectively.

Onions contain polyphenols, anthocyanins, quercetin, kaempferol, flavonoids and their glycosides [13]. Certain species of Allium odorum are highly resistant to diseases caused by nematodes. Onions are beneficial against free radicals and cancer due to their antioxidant and antibacterial activity. It also consists of certain terpenoids, carotenoids, vitamins, phytoestrogens, minerals, etc. [14].

Some researchers write that in people who consume more onions, the risk of cancer of the digestive tract, stomach and respiratory tract is reduced by $50 \%$ [15].

Renal and colon carcinogenesis is inhibited by organosulfur compounds such as S-methylcysteine (SMC), diallyl disulfide (DDS) and S-allylcysteine (SaC) [16]. The risk of Helicobacter poulori infection, which causes stomach cancer due to ulceration, can be reduced by consuming more onion vegetables. In work [17] there are research results that report that quercitin not only increases the effectiveness of ulcer treatment by removing free radicals, but also limits the induction of damage to the gastric mucosa.

It was found that various sulfides, rich in onion extracts, provide protection against tumor growth [18]. The antitumor effects of the compounds have been investigated by examining the beneficial functions of n-propyl thiosulfate (NPTS). The study showed that in vitro proliferation of three human tumor cell lines HL-60, 293 and WiDr was inhibited. In general, 2PTS has potent cell growth inhibitory activity compared to NPTS, which is not the case in WiDr cells, since they are sensitive to both compounds.

A number of authors have studied the effect of garlic on behavior associated with anxiety and depression, as well as on markers of brain oxidation in streptozotocin-induced diabetes (STZ) in rats [19]. Fifty-six male Wistar rats were randomly divided into seven experimental groups ( $n=8 /$ group): control, diabetics + saline, diabetics+garlic, diabetics+imipramine and diabetics+diazepam. Animals received a garlic homogenate $(0.1,0.25$ and $0.5 \mathrm{~g} / \mathrm{kg})$ for 10 days. At the end of treatment, anxiety and depressive behavior was assessed using the elevated cruciform maze (EPM) and forced swim test (FST), respectively. In the brain, superoxide dismutase (SOD) and glutathione peroxidase (GPx) activities and malondialdehyde (MDa) levels were measured. The diabetic+garlic $(0.5 \mathrm{~g} / \mathrm{kg})$ group showed lower anxiety and depressive behavior compared to diabetic rats. In addition, treatment with garlic $(0.5 \mathrm{~g} / \mathrm{kg})$ decreased MDA levels and increased SOD and GPx activity in the brain.

Depression is a common neuropsychiatric disorder. The available pharmacotherapy is ineffective for a significant proportion of patients and has many side effects. Therefore, finding safer drugs for depression is of paramount importance. The study was aimed at identifying the compound responsible for the antidepressant effects of the outer scale extract of Allium cepa (ACE), and elucidating the mechanism of its action. The work [20] studied the possibility of using onion husk extracts in the treatment of depression. In addition, a mouse model of unpredictable chronic moderate stress-induced depressive behavior (UCMS) was used to investigate anti-depression activity and a potential bioactive compound mechanism using behavioral tests. Such tests are forced swim test (FST), sucrose preference test (SPT), open field test (OPT). ACE and its ethyl acetate fraction (EF) demonstrated marked antidepressant-like effects in FST mice in assessing brain oxidative stress and monoamine oxidase and serotonin levels. Chromatographic and spectroscopic studies of EF resulted in the isolation of quercetin and 4'-O-glucosidaquercetin (QG). Animals treated with QG $(20 \mathrm{mg} / \mathrm{kg})$ showed activity similar to that of fluoxetine in mice using FST. Thus, QG was tested for antidepressant activity against UCMS-induced depressive behavior in mice. Treatment of mice exposed to UCMS with QG $(20 \mathrm{mg} / \mathrm{kg})$ improved behavior abnormalities caused by UCMS and restored brain biochemical parameters (oxidative stress, MAO-a activity, and serotonin levels). As a result, the antidepressant effect was confirmed.

The effectiveness of onions in reducing anti-inflammatory diseases is related to its nature as metabolic modulators. Onions play an effective role in fighting fungi and bacteria and increase the shelf life of foods [21].

Steroidal glycosides are a class of natural compounds from the saponin group. Saponins attract the attention of researchers for their biological activity and environmental safety. Plants of the genus Allium are promising in terms of searching for saponin-bearing species [22].

In previous studies, the following results were proved: formulation of new processed cheese with wild onions [23], doses and methods of adding them [24, 25], selection of technological modes for the production of processed cheese with wild onions [26]. 
Recently, the consumer tends to choose environmentally friendly products, without the use of synthetic food additives [27].

The problem associated with meeting the need for products without the use of synthetic food additives, in particular processed cheeses, requires the search for solutions that provide functional properties to processed cheeses, increase nutritional value and increase shelf life. Functional food products are aimed at enhancing immunity and strengthening the health of the population. The main requirements for such products are the absence in their composition of harmful synthetic additives and a high content of natural biologically active substances (BAS), such as aromatic substances, L-ascorbic acid, phenolic compounds, vitamins, minerals, carotenoids, etc. In the production of functional food products, there is a steady interest in environmentally friendly local raw materials.

The source of health improvement for the population of the country is the use of local plant materials growing on the territory of the Republic of Kazakhstan.

From the variety of plant raw materials in Kazakhstan, scientists have selected a variety of plants, vegetables and fruits, legumes, cereals and other crops that have medicinal properties, with a high content of vitamins, minerals, dietary fiber, biologically active substances, etc. [28].

In Kazakhstan, there are resources of onions, including wild ones, which made it possible to carry out the actual development of the technology of processed cheeses using natural additives that have a preserving effect and increase the biological value of the final product.

The analysis shows the need to solve the following unresolved issues: the method of adding filler from the ground part of wild onions in different variations: fresh or dry; rational intervals of the onion dose, as well as the influence of the selected variations on the quantitative content of bioflavonoids, the qualitative characteristics and storage capacity of the finished product in comparison with the control processed sliced cheeses. The solution to the above issues has not been previously considered.

\section{The aim and objectives of research}

The aim of research is to reveal the advantages of the presence of bioflavonoids in the developed processed cheese for a functional purpose with a prolonged shelf life in comparison with traditional processed cheese chunks. A new type of processed cheese with wild onions will expand the range, provide the general population with high-quality, affordable, natural and immune-boosting products.

To achieve the aim, the following objectives were set:

- to develop a recipe and technological modes for the production of processed cheese with wild onions;

- to determine the amount of bioflavonoids in the plant raw material Allium odorum and in processed cheese with the inclusion of wild onions;

- to investigate the conditions and terms of storage of processed cheese with phyto-filler.

\section{Materials and methods of research}

The objects of research were A. odorum plants from the regional flora of the Republic of Kazakhstan and prepared powders from air-dried A. odorum leaves. processed cheese made using vegetable fillers.

In this study, A. odorum was selected from all wild onion species. Unlike other perennial onion species, allspice is characterized by a low fiber content (1.1-1.8\%) and a relatively high content of dry matter (up to $17 \%$ in the bulb, $10.5-11.3 \%$ in the leaves), sugars (10.9-12.1\%). The sugar content of A. odorum is higher than that of white onion. Onion leaves have a significant protein content $-3.8 \%$. Due to this chemical composition, A. odorum leaves almost do not grow thick, retain good taste and tenderness throughout the growing season. The leaves also contain a large amount of vitamins $\mathrm{A}$ and $\mathrm{C}$, minerals (potassium, phosphorus, iron, manganese, zinc, boron, copper, nickel, molybdenum, cobalt). Like garlic, this onion contains allicin, which activates vitamin B1, as well as flavonoids, phenolcarboxylic and triterpenic acids. In comparison with other types of perennial onions, its leaves are the richest in essential oils. A. odorum, like other types of onions, contains many phytoncides that kill pathogenic bacteria. The presence of biologically active substances in this onion increases the body's resistance to various infectious diseases.

Each component in the recipe affects the consistency and organoleptic characteristics of the product. To calculate the formulation of melted cheeses with vegetable filler, the input parameters of the recipe mixture (quantity, content of dry substances, fat, moisture) were set mathematically; highlighted the components that regulate the input parameters of the mixture and do not regulate them; introduced technologically permissible ranges of the content of the components of the new product.

To determine the optimal ratio of the components of the recipe mixture (raw materials, spices, additives, etc.), the optimization of the formulation technology was carried out, since the qualitative characteristics of semi-finished products are controllable parameters, in contrast to the quality characteristics of the final product. Optimization of the parameters of mixtures allows to ensure the receipt of products of a given quality.

The obtained mathematical solution of the processed cheese recipe made it possible to obtain products with different taste characteristics, but the same consistency, depending on the given ratio (the ratio of moisture - $\mathrm{M}$ and dry defatted substances - DDS) M/DDS.

To confirm the functional properties, it was decided to assess the quality of $A$. odorum by the content of flavonoids. The total content of flavonoids was determined by the method of quantitative determination of the sum of flavonoids by UV spectrophotometry in terms of quercetin and luteolin-7-glycoside (cynaroside) [29]. The conditions for the extraction of flavonoids from raw materials by sequential change of ethanol at $96 \%, 70 \%$ and $40 \%$ concentration have been studied. The ratio of raw materials and the total volume of the extractant is 1:100, the time of three-fold extraction in a boiling water bath is 90 minutes.

To calculate the sum of flavonoids in terms of quercetin, the optical density was measured by the intrinsic absorption of the alcoholic extract of A. odorum after hydrolysis at a wavelength of $370 \mathrm{~nm}$. The calculation of the sum of flavonoids was performed using the optical density of a solution of a standard sample of quercetin.

The procedure for obtaining alcoholic extraction from the surface part of A.odorum (extraction method with a sequen- 
tial change of ethanol $96 \%, 70 \%$ and $40 \%$ concentration) is as follows. An exact weighed portion of green onions, about $1.0 \mathrm{~g}$, was placed in a flask with a thin section with a capacity of $150 \mathrm{ml}$. Then $30 \mathrm{ml}$ of $96 \%$ ethanol was added, the flask was connected to a reflux condenser and heated in a water bath for 30 minutes. Then the flask was cooled to room temperature and the contents of the flask were filtered through a paper filter into a $100 \mathrm{ml}$ volumetric flask. Then, by the above method, the extraction was repeated alternately with $70 \%$ and $40 \%$ ethanol. The extracts were filtered through the same filter into the same volumetric flask. The volume of the filtrate was brought to the mark with $96 \%$ alcohol.

The procedure for the quantitative determination of the sum of flavonoids in terms of quercetin is as follows. $10 \mathrm{ml}$ of the obtained alcoholic extract from A. odorum raw material was evaporated in a water bath. The residue was dried in an oven at $110{ }^{\circ} \mathrm{C}$ for 10 minutes, then dissolved in $10 \mathrm{ml}$ of $10 \%$ sulfuric acid. The hydrolysis was carried out in a flask connected to a reflux condenser with heating in a boiling water bath for 2 hours. Under these conditions, only 3-O-glycosides are hydrolyzed, 7-O-glycosides, being more stable, undergo hydrolysis under more severe conditions. The flask was then cooled to room temperature and the contents filtered through a paper filter. The precipitate remaining on the filter was washed with purified water and dissolved in $100 \mathrm{ml}$ of hot $96 \%$ ethanol.

An aliquot of the resulting solution with a volume of $10 \mathrm{ml}$ was brought to the mark in a $25 \mathrm{ml}$ flask with $96 \%$ ethanol. Then the optical density of the resulting solution was measured on a JENWEU 6705 UV/VIS spectrophotometer in the wavelength range of 250 $450 \mathrm{~nm}$ in a cuvette with a layer thickness of $10 \mathrm{~mm}$.

The content of the sum of flavonoids in terms of quercetin was carried out according to the formula (1):

$$
X=\frac{A_{X} \times C_{s t} \times W \times 100}{A_{s t} \times X_{X} \times V_{a}},
$$

where $X$ - content of the sum of flavonoids;

$A_{x}$ - optical density of the test solution;

$C_{s t}$ - concentration of a solution of a standard sample of quercetin;

$W$ - dilution, ml;

$A_{s t}$ - optical density of a solution of a standard sample of quercetin;

$C_{x}$ - concentration of the test solution;

$V_{a}$ - volume of the aliquot, $\mathrm{ml}$.

Assessment of the organoleptic properties of processed cheese according to the standard [30] was carried out on a 30 -point scale (including taste and smell - 15 points, consistency -10 points, color and appearance -5 points).

\section{Results of research of raw materials and processed cheese with $A$. odorum}

5. 1. Development of recipes and technological modes for the production of processed cheese

Fig. 1 shows a diagram of the technology for the production of processed cheese with a filler. Distinctive features of the recipe and technological modes of production are as follows: ready-made vegetable filler is added to the recipe at the end of melting, then the cheese is cooled and packaged.

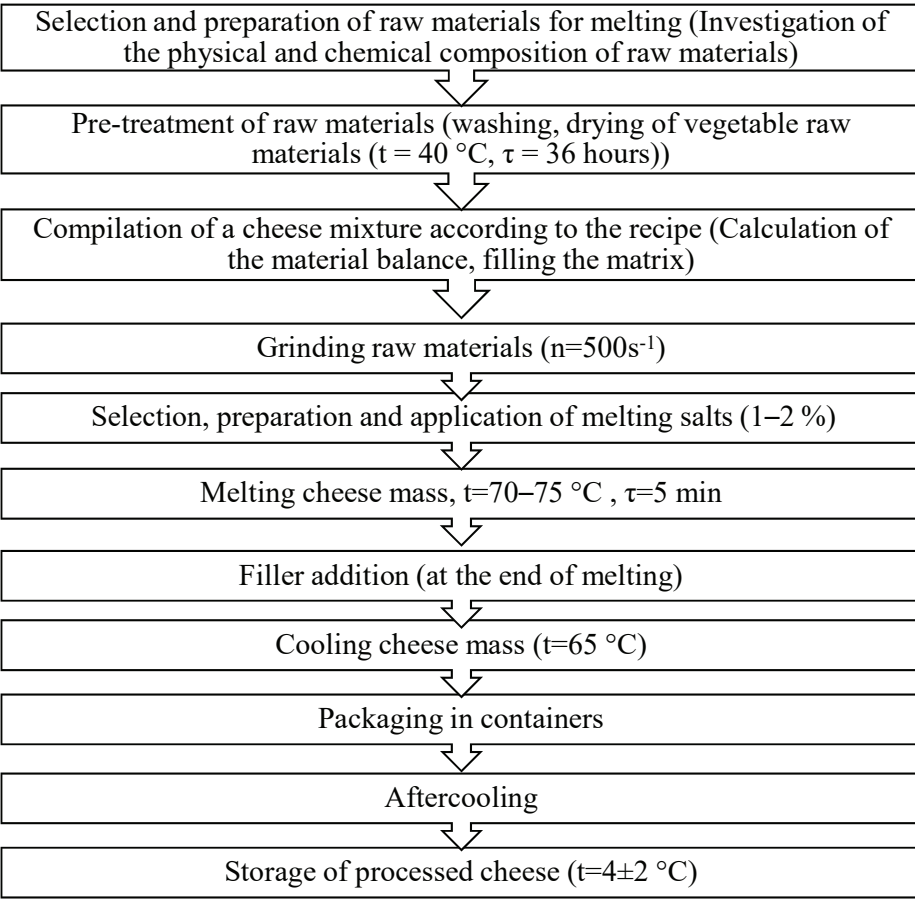

Fig. 1. Technological scheme for the production of processed cheeses with the addition of vegetable raw materials

Table 2 shows the physicochemical indicators of processed cheese samples with different filler content (variations in the dose of plant materials: 1 sample $-1 \%, 2$ sample $-3 \%, 3$ sample $-5 \%$ dried filler in the processed cheese recipe, 4 sample $3 \%$, 5 sample $-5 \%, 6$ sample $-7 \%$, 7 sample $-9 \%$ dose of fresh filler).

As can be seen from Table 2, the M/DDS ratio in 1-3 samples, as well as in 4-6 samples, has the same value. According to the rheological index of the cheese - the limiting shear stress, which is the determining characteristic of the consistency, the samples had identical values, which prove the correctness of the selection of the recipe.

The M/DDS=1.2 at number 3, with a mass fraction of dry substances $45 \%$ and a mass fraction of fat $20 \%$, since this sample received the highest scores, it had a soft delicate consistency, homogeneous mass, pleasant taste and smell.

With the $\mathrm{M} / \mathrm{DDS}=1.5$ under number 6 , with a mass fraction of dry substances of $40 \%$ and a mass fraction of fat of $20 \%$, since this sample received high scores, it had a soft, slightly spreadable consistency, a pleasant slightly cheesecrank taste and aroma.

The organoleptic characteristics of processed cheeses in comparison with the control are shown in Fig. 2.

It has also been found that fresh addition of A.odorum gives a sharp onion aroma, and when dried it gives a slightly chalky aroma to the finished product.

Analyzing the organoleptic indicators presented in the diagram (Fig. 2), it is possible to conclude that the rational dose of plant materials in the form of a powder is $5 \%$ (sample number 3), for fresh plant materials the optimal dose is $7 \%$ (sample number 6 ) for obtaining processed cheese with better sensory characteristics. 
Table 2

Physicochemical characteristics of processed cheese samples

\begin{tabular}{|c|c|c|c|c|c|c|}
\hline Indicator name & Sample 1 & Sample 2 & Sample 3 & Sample 4 & Sample 5 & Sample 6 \\
\hline $\begin{array}{c}\text { Mass fraction of } \\
\text { dry substances, } \%\end{array}$ & $40 \pm 0.1$ & $40 \pm 0.15$ & $40 \pm 0.2$ & $45 \pm 0.1$ & $45 \pm 0.1$ & $45 \pm 0.15$ \\
\hline $\begin{array}{c}\text { Mass fraction of } \\
\text { fat, \% }\end{array}$ & $20 \pm 0.3$ & $20 \pm 0.15$ & $20 \pm 0.21$ & $20 \pm 0.15$ & $20 \pm 0.15$ & $20 \pm 0.18$ \\
\hline M/DDS & $1.5 \pm 0.1$ & $1.5 \pm 0.3$ & $1.50 \pm 0.18$ & $1.20 \pm 0.18$ & $1.20 \pm 0.18$ & $1.2 \pm 0.1$ \\
\hline $\begin{array}{c}\text { Ultimate shear } \\
\text { stress }\end{array}$ & $536 \pm 0.15$ & $537.00 \pm 0.12$ & $536 \pm 0.15$ & $536.00 \pm 0.15$ & $537.0 \pm 0.1$ & $536.00 \pm 0.1$ \\
\hline
\end{tabular}

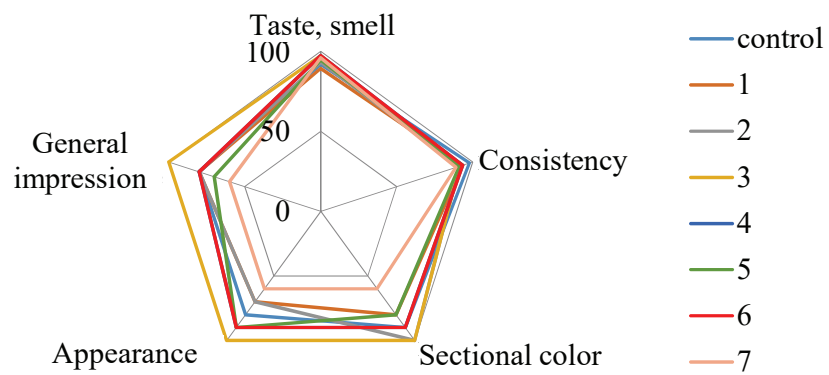

Fig. 2. Organoleptic characteristics of processed cheeses

\section{2. Determination of bioflavonoids in raw materials} and processed cheese

The maximum of the optical density of the UV spectrum of the intrinsic absorption of alcoholic extract from the pen of A. odщrum after hydrolysis coincides with the maximum of the optical density of the UV spectrum of the solution of the state standard sample of quercetin (Fig. 3).

The results of statistical processing of the data of parallel measurements showed that the content of flavonoids in $A$. odorum in terms of quercetin was $(9.4 \pm 0.02438) \%$. The error of a single determination at a confidence level of $98 \%$ was $1.77 \%$. The content of bioflavonoids in the leaves of A.odorum is $10.58 \mathrm{mg}$ per $100 \mathrm{~g}$ of dry matter.

When adding a vegetable filler from wild onions in the form of a powder to processed cheese, the following was established. The results of statistical processing of the data of parallel measurements showed that the content of flavonoids in A. odorum in terms of quercetin was $(1.351 \pm 0.021)$ (Table 3$)$, respectively, in processed cheese with the addition of fresh and processed ground wild onions was $0.241 \%$ (Table 4 ), which indicates the transition of bioflavonoids to the final product.
The relative error of the proposed method is $1.54 \%$. The content of flavonoids in the terrestrial part of A. odorum was $(1.351 \pm 0.021) \%$.

Table 3

Results of the quantitative determination of the sum of flavonoids in processed cheese with $A$. odorum dry powder

\begin{tabular}{|c|c|c|c|}
\hline$\overline{\boldsymbol{X}}(\%)$ & $\left(\bar{X}-X_{i}\right)$ & $\left(\bar{X}-X_{i}\right)^{2}$ & Metrological characteristics \\
\hline 1,311 & 0.040 & 0.00159 & $\overline{\boldsymbol{X}}=1.351$ \\
\hline 1,357 & -0.006 & 0.00004 & $\sum\left(\overline{\boldsymbol{X}}-\boldsymbol{X}_{\boldsymbol{i}}\right)^{2}=0.002$ \\
\hline 1,365 & -0.014 & 0.00020 & \multirow{2}{*}{$S_{x}=\sqrt{\frac{\sum\left(\overline{\boldsymbol{X}}-\boldsymbol{X}_{\boldsymbol{i}}\right)^{2}}{n(n-1)}}=0.0081$} \\
\hline 1,359 & -0.008 & 0.00007 & $\Delta X^{2} S_{x} \cdot t_{x}=0.021$ \\
\hline 1,354 & -0.003 & 0.00001 & $\varepsilon=1.54$ \\
\hline 1,359 & -0.008 & 0.00007 & $\varepsilon$ \\
\hline
\end{tabular}

Table 4

Results of quantitative determination of the sum of flavonoids in processed cheese with $A$. odorum in terms of quercetin

\begin{tabular}{|c|c|c|c|}
\hline$\overline{\boldsymbol{X}}(\%)$ & $\left(\bar{X}-X_{i}\right)$ & $\left(\bar{X}-X_{i}\right)^{2}$ & Metrological characteristics \\
\hline 0.241 & 0.000 & 0.00000 & $\overline{\boldsymbol{X}}=0.241$ \\
\hline 0.237 & 0.004 & 0.00002 & $\sum\left(\overline{\boldsymbol{X}}-\boldsymbol{X}_{i}\right)^{2}=0.00006$ \\
\hline 0.243 & -0.002 & 0.00000 & $S_{x}=\sqrt{\frac{\sum\left(\overline{\boldsymbol{X}}-\boldsymbol{X}_{\boldsymbol{i}}\right)^{2}}{n(n-1)}}=0.0014$ \\
\hline 0.247 & -0.006 & 0.00003 & $\Delta X=S_{x} \cdot t_{x}=0.04$ \\
\hline 0.239 & 0.002 & 0.00001 & $\varepsilon=1.571$ \\
\hline 0.2414 & 0.000 & 0.00000 & $\varepsilon$ \\
\hline
\end{tabular}

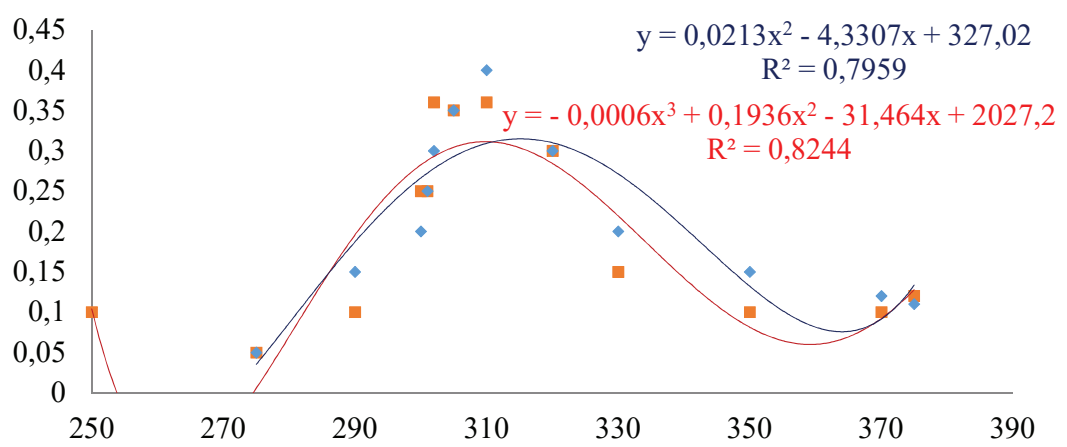

- Row 2 Row $1-$ Polynomial (Row 2)—Polynomial (Row 2)

Fig. 3. Optical density of $A$. odorum extract in comparison with quercetin standard 
5. 3. Determination of the effect of the filler on the shelf life of processed cheese

To determine the shelf life, let's study the qualitative and quantitative composition of the microflora of a control sample of processed slice cheese and developed processed cheese with vegetable filler during refrigerated storage at a temperature of $(2 \pm 2)^{\circ} \mathrm{C}$ for 70 days (Fig. 4)

During 20 days of storage at a temperature of 0 to $4{ }^{\circ} \mathrm{C}$, no bacterial growth was noted in the processed cheese samples, and there were no changes in organoleptic parameters. Further, up to 70 days of storage in $1 \mathrm{~g}$ of processed cheese developed by us, no bacteria of the Escherichia coli group were found, yeast and molds were contained in much smaller quantities than allowed by the standards, compared with the control. The number of QMAFAnM also did not exceed the permissible values $\left(1 \times 10^{3}\right)$.

The normative value of yeast in processed cheeses is 100. Comparison of the dynamics of yeast in the control and experimental samples showed that during storage up to 70 days in the control there is a sharp growth of yeast. In the experimental sample, even after 65 days, the amount of yeast is low, not even reaching half of the standard values. Thus, the positive effect of the vegetable filler from Allium odorum on the quality of processed cheeses during storage at low positive temperatures has been proven (Fig. 5).

In accordance with the current standard [31], processed cheeses of this group are stored for up to 45 days at temperatures from 4 to $0{ }^{\circ} \mathrm{C}$, and under storage conditions from 0 to $4{ }^{\circ} \mathrm{C}-$ up to 30 days. In accordance with food safety standards, the amount of yeast should be no more than 50. As can be seen from Fig. 4, the processed cheese of the prototype is significantly superior to the control sample, despite the fact that the content of melting salts in the recipe is 2 times less and there are no regulators and preservatives in the recipe. In recent years, in the production of processed cheeses, there has been a tendency to reduce the amount of added melting salts - synthetic polyphosphates. The developed technology made it possible to reduce the content of melting salts from $5-10 \%$ (the classic recipe for processed cheese chunks) to 1.5-2 \% (Fig. 1), in addition, the developed recipe does not contain synthetic food additives - regulators, preservatives, taste consistency correctors and aroma, which makes it possible to classify the developed cheese as environmentally friendly food.

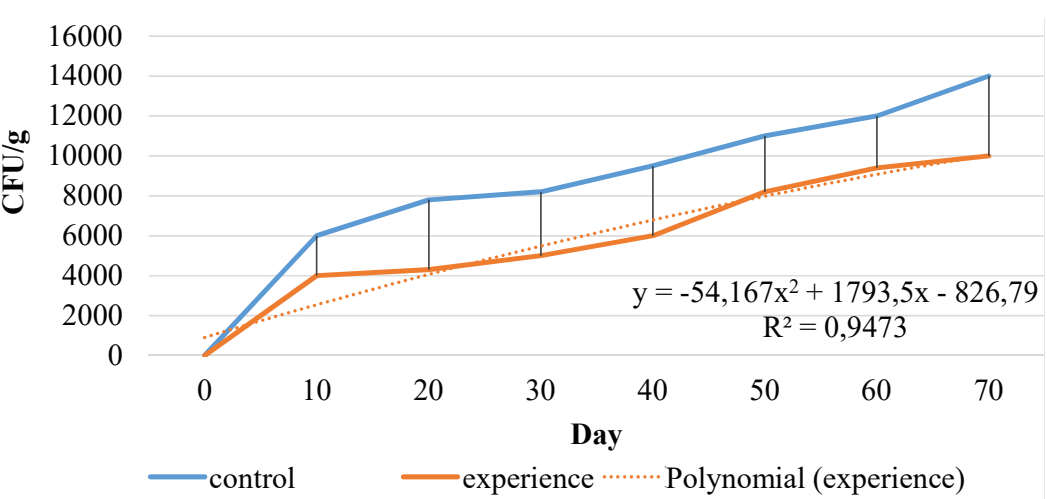

Fig. 4. The number of mesophilic aerobic and facultative anaerobic microorganisms when stored at a refrigeratedtemperature for 70 days

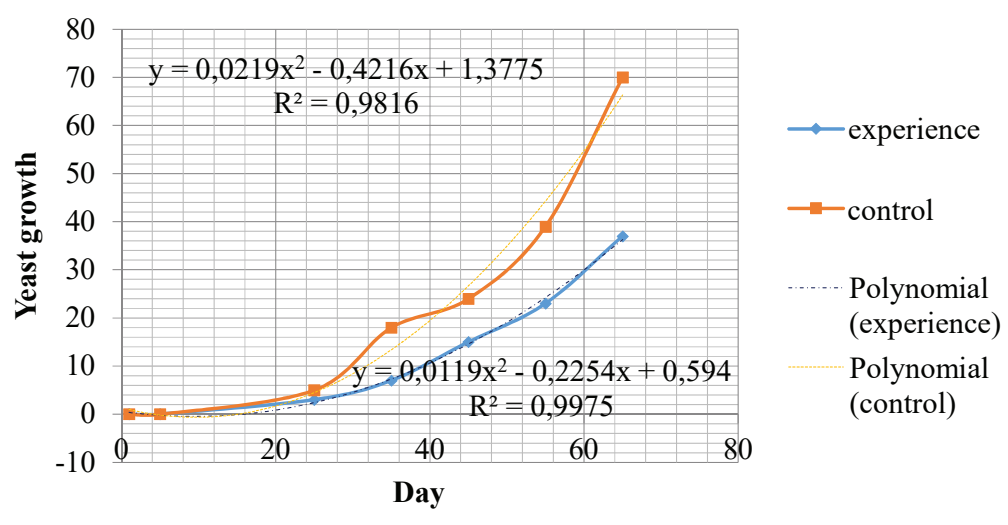

Fig. 5. Dynamics of yeast growth during storage up to 70 days at refrigerated temperature

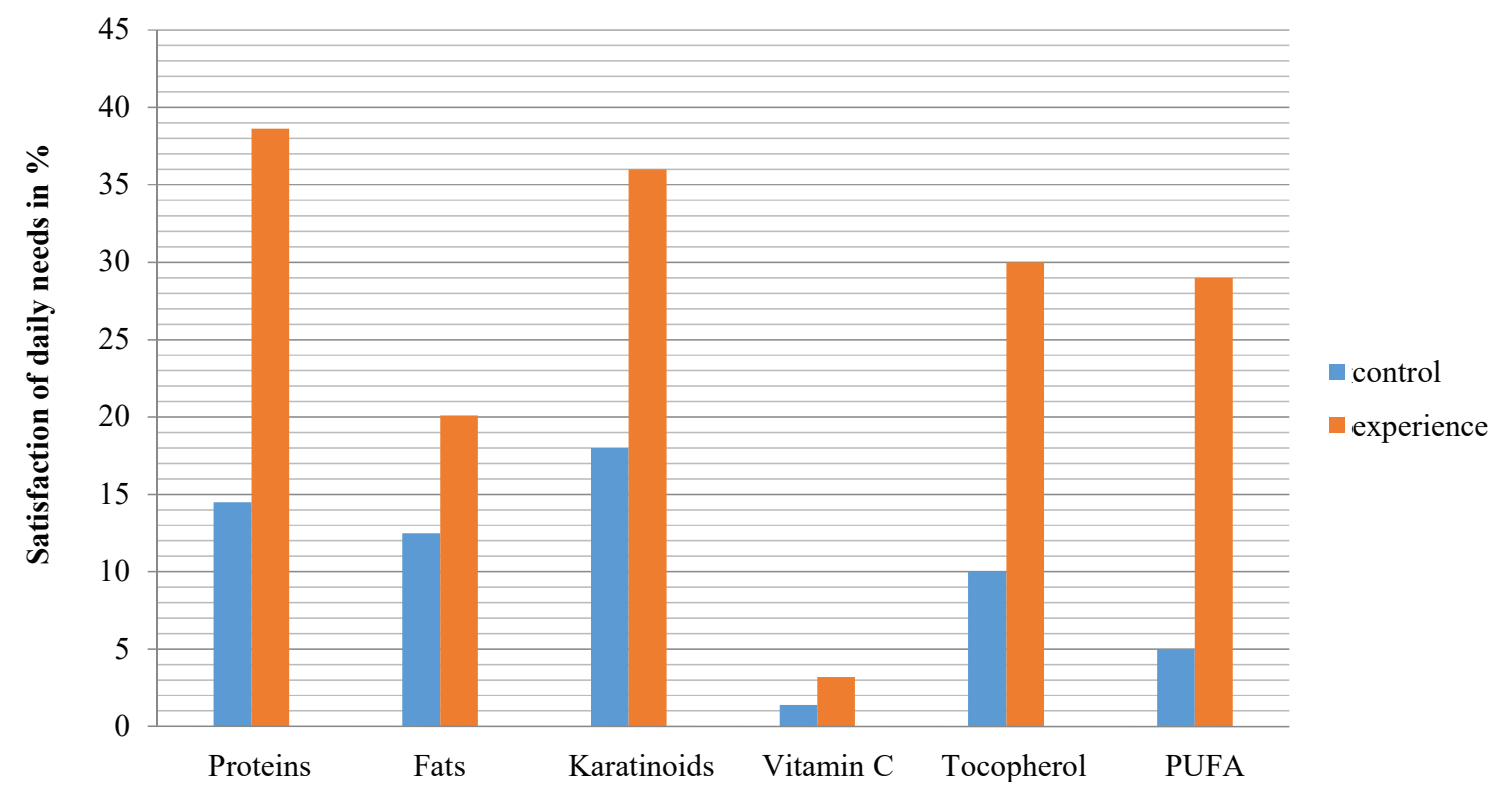

Fig. 6. Satisfaction of the daily requirement in comparison with control 


\section{Discussion of the results of the study of processed cheese with wild onion filling}

A rational dose of $A$.odorum addition to the processed cheese recipe in the form of powder (5\%) and fresh (7\%) has been chosen. The color of the cheese ranges from light salad to green. When dry A. odorum powder is added, the color of the cheese is light green with a splash of filler [32].

According to the results of the experiments, the following samples were identified as the best:

1. With the M/ DSS ratio=1.2 at number 3, with a mass fraction of dry substances $45 \%$ and a mass fraction of fat $20 \%$, since this sample received the highest scores, had a soft delicate consistency, homogeneous mass, pleasant taste and smell.

2. With the ratio $\mathrm{M} / \mathrm{DSS}$ ratio=1.5 at number 6 , with a mass fraction of dry substances $40 \%$ and a mass fraction of fat $20 \%$, since this sample received high scores, had a soft, slightly spreadable consistency, a pleasant slightly cheesecrank taste and aroma.

The rational dose of a mixture of melting salts was determined experimentally, the best organoleptic characteristics of melted cheese - 26.1 points, were established by adding $1.0 \%$ of a mixture of melting salts at a melting temperature of 75.2 to $79.8^{\circ} \mathrm{C}$.

With the addition of $1.5 \%$ of a mixture of melting salts, the change in the score of the melted cheese ranged from 22 to 26.5 points. The best organoleptic characteristics were observed in cheeses in the production of which the maximum stirring speed $\left(500 \mathrm{~s}^{-1}\right)$ and melting temperatures from 75 to $79.2{ }^{\circ} \mathrm{C}$ were used.

When a $2 \%$ mixture of melting salts was added, the highest point value was observed - 29 points of organoleptic characteristics of cheeses: the melting temperature was in the range of $75 \ldots 77.8^{\circ} \mathrm{C}$.

From Fig. 6 it follows that the prototype of processed cheese with a vegetable filler of local origin compares favorably with the control sample. The content of carotenoids in the experimental cheese exceeded 2 times, the content of vitamin $\mathrm{E}$ exceeded 3 times, vitamin $\mathrm{C}-3$ times, and PUFA, which contains essential fatty acids $\omega 6$ and $\omega 3$, due to the introduced wild onions - 6 times compared to control (lumped processed cheese).

Thanks to the addition of processed cheese, the shelf life has increased, the nutritional value of processed cheese has been increased. At the same time, the formulation contains no synthetic additives, consistency improvers, acidity regulators, etc. The advantages of this study are the study of the filler and its effect on the composition and shelf life of processed cheese, the possibility of producing processed cheese without synthetic additives. A limitation of the study is that the introduced wild onion, depending on the growing area and soil, can collect a different ratio of Selenium and other substances. In the future, it is planned to isolate saponins and study the composition of processed cheeses using saponins. A new type of processed cheese with a phyto-filler - Allium odorum - shows functional properties due to the appearance of flavonoids, a significant increase in B vitamins, carotenoids, tocopherols, and essential fatty acids $\omega 6$ and $\omega 3$.

\section{Conclusions}

1. When developing technological modes, the properties of wild onions were taken into account, when developing a recipe mixture, the physicochemical indicators of ingredients were taken into account and the material balance was calculated, and the recipe was optimized. When producing processed cheeses with wild onions according to an optimized recipe, wild onions were added fresh and dry. Of all the samples produced, two were selected:

- with the M/DSS ratio=1.2 at number 3, with a mass fraction of dry substances of $45 \%$ and a mass fraction of fat of $20 \%$, since this sample received the highest points, had a soft delicate consistency, a homogeneous mass, a pleasant onion taste and smell;

- with the M/DSS ratio=1.5 at number 6 , with a mass fraction of dry substances of $40 \%$ and a mass fraction of fat of $20 \%$, since this sample received high scores, had a soft, slightly spreadable consistency, a pleasant slightly cheesecrank taste and aroma.

These samples received the highest score according to the tasting assessment.

2. The content of bioflavonoids in terms of quercetin was in the aerial part of A. odorum onions $(9.4 \pm 0.02438) \%$, which covers the daily requirement of the body by $5 \%$. Biological properties of quercetin: immunostimulating effect (increases the activity of phagocytes, T- and B-lymphocytes; increases the production of antibodies, reduces the manifestations of secondary immunodeficiency, the incidence of viral infections); oncoprotective effect due to a decrease in the damaging effect of oxygen radicals on the genetic apparatus; antioxidant protection; positive impact on cardiovascular diseases, etc.

In processed cheese with the addition of A. odorum dry onion powder, the content of bioflavonoids in terms of quercetin was $(1.351 \pm 0.021) \%$ and $(0.241 \pm 0.04) \%$. A rational dose of adding wild onion filler in the form of powder (5\%) and fresh $(7 \%)$ to the recipe of processed cheeses has been chosen.

3 . The addition of this vegetable filler has a positive effect on the shelf life of processed cheese. When stored for up to 70 days at a temperature of $(2 \pm 2){ }^{\circ} \mathrm{C}$, the microbiological indicators of the control version of the slice cheese deteriorate sharply, while the experimental sample shows microflora stability on the $70^{\text {th }}$ day.

\section{References}

1. Seydumanova, M. (2013). Pischevaya promyshlennost': perspektivy razvitiya. Delovoy Kazahctan. Available at: https://foodexpo.kz/ru/ press-tsentr/novosti/novosti-uchastnikov/82-25-12-2013dk

2. MR 2.3.1.1915-04. Metodicheskie rekomendatsii. 2.3.1. Ratsional'noe pitanie. Rekomenduemye urovni potrebleniya pischevyh i biologicheski aktivnyh veschestv. Available at: https://docs.cntd.ru/document/1200037560

3. Sozdanie kachestvenno novyh produktov s zadannymi svoystvami. Available at: https://www.oborud.info/news/?t=10921

4. Martins, N., Petropoulos, S., Ferreira, I. C. F. R. (2016). Chemical composition and bioactive compounds of garlic (Allium sativum L.) as affected by pre- and post-harvest conditions: A review. Food Chemistry, 211, 41-50. doi: https://doi.org/10.1016/j.foodchem.2016.05.029 
5. Lanzotti, V. (2006). The analysis of onion and garlic. Journal of Chromatography A, 1112 (1-2), 3-22. doi: https://doi.org/10.1016/ j.chroma.2005.12.016

6. Krishnakantha, T. P., Lokesh, B. R. (1993). Scavenging of superoxide anions by spice principles. Indian Journal of Biochemistry \& Biophysics, 30 (2), 133-134.

7. Pulla Reddy, A. C., Lokesh, B. R. (1992). Studies on spice principles as antioxidants in the inhibition of lipid peroxidation of rat liver microsomes. Molecular and Cellular Biochemistry, 111 (1-2). doi: https://doi.org/10.1007/bf00229582

8. Onyeoziri, U. P., Romanus, E. N., Onyekachukwu, U. I. (2016). Assessment of antioxidant capacities and phenolic contents of nigerian cultivars of onions (Allium cepa L) and garlic (Allium sativum L). Pakistan Journal of Pharmaceutical Sciences, 29 (4), $1183-1188$.

9. Alimardanova, M. K., Tlevlesova, D. A., Simov, Z., Dimitrov, D., Matibayeva, A. (2015). Incorporating Allium odorum as a Vegetable Ingredient of Processed Cheeses. Research Journal of Pharmaceutical, Biological and Chemical Sciences, 6 (3), 330-338. Available at: https://www.rjpbcs.com/pdf/2015_6(3)/[44].pdf

10. Cao, Y., Gu, W., Zhang, J., Chu, Y., Ye, X., Hu, Y., Chen, J. (2013). Effects of chitosan, aqueous extract of ginger, onion and garlic on quality and shelf life of stewed-pork during refrigerated storage. Food Chemistry, 141 (3), 1655-1660. doi: https://doi.org/10.1016/j.foodchem.2013.04.084

11. Meena, M. R. (1992). Studies on antimicrobial activity of various spices and their oils. Indian Agricultural Research Institute.

12. Ashwini, M., Balaganesh, J., Balamurugan, S., Murugan, S. B., Sathishkumar, R. (2013). Antioxidant Activity in in Vivo and in Vivo Cultures of Onion Varieties (Bellary and CO 3). Food and Nutrition Sciences, 04 (09), 918-923. doi: https://doi.org/10.4236/ fns.2013.49119

13. Calucci, L., Pinzino, C., Zandomeneghi, M., Capocchi, A., Ghiringhelli, S., Saviozzi, F. et. al. (2003). Effects of $\gamma$-Irradiation on the Free Radical and Antioxidant Contents in Nine Aromatic Herbs and Spices. Journal of Agricultural and Food Chemistry, 51 (4), 927-934. doi: https://doi.org/10.1021/jf020739n

14. Wiczkowski, W., Németh, K., Buciński, A., Piskuła, M. K. (2003). Bioavailability of quercetin from flesh scales and dry skin of onion in rats. Polish Journal of Food and Nutrition Sciences, 12 (SI 1), 95-99. Available at: http://journal.pan.olsztyn.pl/ BIOAVAILABILITY-OF-QUERCETIN-FROM-FLESH-SCALES-AND-DRY-SKIN-OF-ONION-IN-RATS,98567,0,2.html

15. Turati, F., Rossi, M., Pelucchi, C., Levi, F., La Vecchia, C. (2015). Fruit and vegetables and cancer risk: a review of southern European studies. British Journal of Nutrition, 113 (S2), S102-S110. doi: https://doi.org/10.1017/s0007114515000148

16. Fukushima, S., Takada, N., Hori, T., Wanibuchi, H. (1997). Cancer prevention by organosulfur compounds from garlic and onion. Journal of Cellular Biochemistry, 67 (S27), 100-105. doi: https://doi.org/10.1002/(sici)1097-4644(1997)27+<100::aid-jcb16>3.0.co;2-r

17. Ahmed, O., Abourehab, M., Khaled, K., Sarhan, H. (2015). Evaluation of combined famotidine with quercetin for the treatment of peptic ulcer: in vivo animal study. Drug Design, Development and Therapy, 9, 2159-2169. doi: https://doi.org/10.2147/dddt.s81109

18. Craig, W. J. (1997). Phytochemicals. Journal of the American Dietetic Association, 97 (10), S199-S204. doi: https://doi.org/ 10.1016/s0002-8223(97)00765-7

19. Rahmani, G., Farajdokht, F., Mohaddes, G., Babri, S., Ebrahimi, V., Ebrahimi, H. (2018). Garlic (Allium sativum) improves anxietyand depressive-related behaviors and brain oxidative stress in diabetic rats. Archives of Physiology and Biochemistry, 126 (2), 95-100. doi: https://doi.org/10.1080/13813455.2018.1494746

20. Singh, V., Chauhan, G., Shri, R. (2021). Anti-depressant like effects of quercetin 4'-O-glucoside from Allium cepa via regulation of brain oxidative stress and monoamine levels in mice subjected to unpredictable chronic mild stress. Nutritional Neuroscience, 24 (1), 35-44. doi: https://doi.org/10.1080/1028415x.2019.1587247

21. Arshad, M. S., Sohaib, M., Nadeem, M., Saeed, F., Imran, A., Javed, A. et. al. (2017). Status and trends of nutraceuticals from onion and onion by-products: A critical review. Cogent Food \& Agriculture, 3 (1), 1280254. doi: https://doi.org/10.1080/ 23311932.2017.1280254

22. Tolkacheva, N. V., Ezhov, V. N., Ol'hovskaya, V. A., Chirva, V. Ya., Komarovskaya-Porohnyavets, E. Z., Novikov, V. P. Steroidnye glikozidy soplodiy Allium cyrillii (Alliaceae) i ih biologicheskaya aktivnost'. Available at: http://www.rusnauka.com/36_PVMN_2013/ Biologia/2_153576.doc.htm

23. Alimardanova, M. K., Tlevlesova, D. A., Dihanbaeva, F. T., Smailova, J. (2015). Formation of consumer properties of the new types of processed cheese using mathematical modeling. VESTNIK KazNTU, 4 (110), 185-190. Available at: https://official.satbayev.university/download/document/7127/\%D0\%92\%D0\%95\%D0\%A1\%D0\%A2\%D0\%9D\%D0\%98\%D0\% 9A-2015\%20\%E2\%84\%964.pdf

24. Alimardanova, M. K., Tlevlesova, D. A. (2015). The study of the rheological characteristics of processed cheese with a vegetable filling, local origin. VESTNIK KazNTU, 4 (110), 158-161. Available at: https://official.satbayev.university/download/document/ 7127/\%D0\%92\%D0\%95\%D0\%A1\%D0\%A2\%D0\%9D\%D0\%98\%D0\%9A-2015\%20\%E2\%84\%964.pdf

25. Tlevlesov, D. A., Alimardanova, M. K. (2014). Physical is the chemical properties of processed cheese with vegetable filler. Vestnik Gosudarstvennogo universiteta imeni Shakarima goroda Semey, 3 (67), 80-84. 
26. Tlevlessova, D. A. (2015). Effect of component composition on the rheological properties of product. News of the National Academy of Sciences of the Republic of Kazakhstan. Series of Agricultural Sciences, 4, 77-86. Available at: http://nblib.library.kz/elib/library. kz/Jurnal/\%D0\%90\%D0\%B3\%D1\%80\%D0\%B0\%D1\%80\%D0\%BD\%D0\%B0\%D1\%8F_04_2015/Tlevlessova\%20D\%20A.pdf

27. Eda kak istochnik zdorov'ya. Available at: https://issek.hse.ru/trendletter/news/164655928.html

28. Petchenko, V. I., Alimardanova, M. K., Smagulova, A. K., Akpanov, Zh. K. (2020). Sravnitel'naya harakteristika kachestva plavlenogo syra «President»s dobavleniem mestnogo rastitel'nogo syr'ya. Scientific Achievements of Modern Society: Abstracts of XI International Scientific and Practical Conference. Liverpool, 412-418. Available at: https://sci-conf.com.ua/wp-content/ uploads/2020/06/SCIENTIFIC-ACHIEVEMENTS-OF-MODERN-SOCIETY-24-26.06.2020.pdf

29. Lesovaya, Zh. S., Pisarev, D. I., Novikov, O. O., Romanova, T. A. (2010). Development of methods of quantitative determination of flavonoids in Alchemilla vulgaris LSL. Nauchnye vedomosti Belgorodskogo gosudarstvennogo universiteta. Seriya: Meditsina i farmatsiya, 12/2 (22), 145-149. Available at: http://dspace.bsu.edu.ru/bitstream/123456789/967/1/Lesovaya\%20Zh.S..pdf

30. GOST 33630-2015. Cheese and processed cheese. Methods for control of organoleptic properties. Available at: https://docs.cntd.ru/ document/1200127756

31. ST RK 715-95. Syry plavlenye. Tekhnicheskie usloviya. Available at: https://files.stroyinf.ru/Index2/1/4293740/4293740682.htm

32. Kulazhanov, K. S., Tlevlesova, D. A., Alimardanova, M. K. (2014). Pat. No. 30587 KZ. Sposob proizvodstva plavlenogo syra s rastitel'nymi napolnitelyami. zayavl. 01.08.2014; opubl. 16.11.2015. Available at: https://kzpatents.com/0-30587-sposobproizvodstva-plavlenogo-syra-s-rastitelnymi-napolnitelyami.html 